\title{
MicroRNA-214 suppresses the viability, migration and invasion of human colorectal carcinoma cells via targeting transglutaminase 2
}

\author{
HUIGUO SHAN $^{1}$, XUEFENG ZHOU $^{1}$ and CHUANJUN CHEN ${ }^{2}$ \\ ${ }^{1}$ Department of Oncology, The Affiliated Dongtai Hospital of Nantong University, Dongtai, Jiangsu 224200; \\ ${ }^{2}$ Department of Medical Oncology, Xinchang People's Hospital, Shaoxing, Zhejiang 312500, P.R. China
}

Received June 1, 2018; Accepted February 21, 2019

DOI: $10.3892 / \mathrm{mmr} .2019 .10325$

\begin{abstract}
Colorectal carcinoma (CRC) is a common malignancy of the digestive tract. MicroRNA (miR)-214 is considered a key hub that controls tumor networks; therefore, the effects of miR-214 on CRC were examined and its target gene was investigated in this study. The expression levels of transglutaminase 2 (TGM2) and miR-214 were detected in CRC and adjacent normal tissues by reverse transcription-quantitative polymerase chain reaction (RT-qPCR) and western blotting, and luciferase activity was analyzed by dual luciferase reporter analysis. In addition, cell viability, invasion and migration were measured by Cell Counting kit- 8 and Transwell assays, respectively. The expression levels of epithelial-mesenchymal transition-related proteins, and phosphoinositide-3 kinase $(\mathrm{PI} 3 \mathrm{~K}) /$ protein kinase $\mathrm{B}(\mathrm{Akt})$ signaling-associated factors were detected using RT-qPCR and western blotting. The results demonstrated that miR-214 expression was downregulated in CRC tissue, whereas TGM2 expression was upregulated. According to TargetScan prediction, miR-214 possesses a binding site to TGM2. In addition, transfection with miR-214 mimics markedly suppressed the viability of LoVo cells. miR-214 overexpression also inhibited cell invasion and migration by increasing E-cadherin and tissue inhibitor of metalloproteinases-2 expression, and decreasing matrix metalloproteinase (MMP)-2 and MMP-9 expression. Furthermore, miR-214 downregulated phosphorylation of PI3K and Akt; however, the expression levels of total PI3K and Akt were not affected by miR-214. In conclusion, this study indicated that TGM2 was a target gene of miR-214, and a negative correlation between miR-214 and TGM2 expression was determined in CRC. Notably, miR-214 markedly suppressed the viability, invasion and migration of CRC cells, which may be associated with a downregulation in PI3K/Akt signaling. These findings
\end{abstract}

Correspondence to: Dr Chuanjun Chen, Department of Medical Oncology, Xinchang People's Hospital, 117 Middle Gushan Road, Xinchang, Shaoxing, Zhejiang 312500, P.R. China

E-mail: chuanjunc_chencj@163.com

Key words: colorectal carcinoma, microRNA-214, transglutaminase 2, phosphoinositide 3-kinase/protein kinase B signaling suggested that miR-214 may be considered a novel target for the treatment of CRC.

\section{Introduction}

Colorectal carcinoma (CRC) is a common malignancy of the digestive tract (1), the incidence of which is increasing annually in China (2). If patients with CRC metastasis in advanced stages are not promptly treated, their average survival is only 5-6 months $(3,4)$, and the main causes of CRC-associated mortality are invasion and metastasis $(5,6)$. Therefore, it is particularly important to identify novel tumor markers to inhibit tumor metastasis.

In the occurrence and development of invasive carcinoma from atypical hyperplasia and carcinoma in situ, the destruction of epithelial integrity is an important event (7). The first stage of tumor invasion and metastasis includes destruction of the intact epithelial structure and acquisition of stromal cell characteristics; this process is known as epithelial-mesenchymal transition (EMT). EMT is a phenomenon during which epithelial cells convert to interstitial cells under specific physiological and pathological conditions (8). It has been reported that EMT is closely associated with tumor invasion and metastasis, and that it serves a key role in in situ infiltration and distant metastasis of various types of cancer $(9,10)$. Various cancer cells can undergo partial or complete EMT (11-13).

MicroRNAs (miRNAs/miRs) are a series of endogenous non-coding small RNA molecules, usually 18-25 nt in length (14). miRNAs suppress protein translation through binding to the 3'-untranslated region (3'UTR) of target gene mRNA $(15,16)$, miRNAs serve a key role in translation inhibition following gene transcription. In recent years, increasing experimental evidence has demonstrated that abnormal miRNA expression in tumor cells is closely associated with the occurrence of tumors. Different degrees of abnormal miRNA expression (17-20) can be detected in all types of human cancer, including CRC. In addition, miRNAs have been reported to exert a strong regulatory effect on EMT (21-23). Notably, miR-214 is considered a key hub that controls tumor networks (24); however, the role and mechanism of miR-214 in the development of CRC are currently unclear.

In the present study, the expression of miR-214 was detected in CRC tissues, and its target gene was identified. Furthermore, the effects of miR-214 on viability and motility 
of CRC cells were determined, and the underlying molecular mechanism was analyzed.

\section{Materials and methods}

Tissue source. Between November 2016 and December 2017, 36 CRC and adjacent normal tissues were collected from patients with CRC that were admitted to The Affiliated Dongtai Hospital of Nantong University (Dongtai, China). Written informed consent was obtained from patients permitting their tissues to be used. The present study was approved by the Ethics Committee of The Affiliated Dongtai Hospital of Nantong University (approval no. 201501218).

Cell line. The LoVo human colon adenocarcinoma cell line (American Type Culture Collection, Manassas, VA, USA) was maintained in RPMI-1640 medium (M\&C Gene Technology Co., Ltd., Beijing, China) supplemented with $10 \%$ fetal bovine serum (FBS; Gibco; Thermo Fisher Scientific, Inc., Waltham, $\mathrm{MA}, \mathrm{USA}$ ) at $37^{\circ} \mathrm{C}$ in an incubator containing $5 \% \mathrm{CO}_{2}$.

Cell transfection. miR-214 mimics and miRNA mimics control were purchased from Genomeditech (Shanghai, China). miR-214 mimics sense, 5'-ACAGCAGGCACAGAC AGGCAGU-3', and antisense, 5'-UGCCUGUCUGUGCCU GCUGUUU-3'; mimics control sense, 5'-UUCUCCGAACGU GUCACGUTT-3' , and antisense, 5'-ACGUGACACGUUCGG AGAATT-3'. Using Lipofectamine ${ }^{\circledR} 3000$ reagent (Invitrogen; Thermo Fisher Scientific, Inc.), miR-214 mimics (50 nM; mimic group) or miRNA mimics control (50 nM; mock group) were transfected into LoVo cells $\left(60-80 \%\right.$ confluence) at $37^{\circ} \mathrm{C}$ for $24 \mathrm{~h}$, and the control group were treated with PBS. In addition, cells were treated with $50 \mathrm{ng} / \mathrm{ml}$ insulin-like growth factor-1 (IGF-1; AmyJet Scientific, Wuhan, China) for $24 \mathrm{~h}$ at $37^{\circ} \mathrm{C}$, in order to activate phosphoinositide 3-kinase (PI3K) (25).

Dual luciferase reporter assay. TargetScan version 7.2 (http://www.targetscan.org/vert_72/) was used to predict the binding site between the 3'-UTR of transglutaminase 2 (TGM2) and miR-214. For the dual luciferase reporter experiments, the 3'-UTR of TGM2 gene and a mutant (mut) 3'-UTR of TGM2, which was constructed using a Site-Directed Mutagenesis kit (Stratagene; Agilent Technologies, Inc., Santa Clara, CA, USA) according to manufacturer's protocol, were amplified by PCR. The thermocycling conditions were as follows: Initial denaturation at $95^{\circ} \mathrm{C}$ for $30 \mathrm{sec}$, followed by 18 cycles of denaturation at $95^{\circ} \mathrm{C}$ for $30 \mathrm{sec}, 55^{\circ} \mathrm{C}$ for $1 \mathrm{~min}$ and $68^{\circ} \mathrm{C}$ for $2 \mathrm{~min}$, with a final elongation step at $68^{\circ} \mathrm{C}$ for $5 \mathrm{~min}$. Both PCR products were cloned into the psiCHECK-2 vector (Promega Corporation, Madison, WI, USA) to generate TGM2-3'-UTR plasmids, and the TGM2-3'-UTR mut plamids, respectively. Then, 293 cells (American Type Culture Collection, Manassas, VA, USA) cultured in DMEM (HyClone; GE Healthcare Life Sciences; Logan, UT, USA) with $10 \% \mathrm{FBS}, 100 \mathrm{U} / \mathrm{ml}$ penicillin and $100 \mu \mathrm{g} / \mathrm{ml}$ streptomycin at $37^{\circ} \mathrm{C}$ in an incubator with $5 \% \mathrm{CO}_{2}$, were co-transfected with miR-214 mimics/miRNA mimics (50 nM) and TGM2-3'-UTR/TGM2-3'-UTR mut plasmids (50 ng/ $\mu \mathrm{l}$ ) using Lipofectamine ${ }^{\circledR} 3000$ reagent at $37^{\circ} \mathrm{C}$ for $24 \mathrm{~h}$. After $24 \mathrm{~h}$, the cells were lysed with 1X passive lysis buffer (50 $\mu \mathrm{l}$ ) for $15 \mathrm{~min}$ at room temperature, and the suspension was then transferred into a black enzyme plate. Then, the Luciferase assay reagent II $(100 \mu \mathrm{l})$ and $1 \mathrm{X}$ Stop\&Glo ${ }^{\circledR}$ reagent (100 $\mu$ l) (Promega Corporation) were added to the cells, and luciferase activity was detected using the GloMax ${ }^{\circledR}$ Discover Multimode Microplate Reader (cat. no. GM3000; Promega Corporation) according to the manufacturer's instructions. Luciferase activity was normalized to Renilla luciferase.

Reverse transcription-quantitative PCR (RT-qPCR). Total RNA was extracted from cells and tissues using TRIzol ${ }^{\circledR}$ reagent (Invitrogen; Thermo Fisher Scientific, Inc.). RT was conducted to synthesize cDNA from $2 \mu \mathrm{g}$ RNA using $\mathrm{H}$ BeyoRT II First Strand cDNA Synthesis kit (Beyotime Institute of Biotechnology, Haimen, China), according to manufacturer's protocol. The primer sequences are listed in Table I. cDNA was amplified using SYBR Green qPCR Master Mix (MedChemExpress, Monmouth Junction, NJ, USA). The conditions of amplification were as follows: Pre-denaturation at $95^{\circ} \mathrm{C}$ for $10 \mathrm{sec}$, followed by 30 cycles of denaturation at $95^{\circ} \mathrm{C}$ for $5 \mathrm{sec}$ and $62^{\circ} \mathrm{C}$ for $25 \mathrm{sec}$, and a final elongation step at $70^{\circ} \mathrm{C}$ for $30 \mathrm{~min}$. The internal controls were U6 and GAPDH. Gene expression was calculated and quantified using the $2^{-\Delta \Delta C q}$ method (26).

Western blot analysis. Total proteins were extracted from cells and tissues using radioimmunoprecipitation assay buffer (Beijing Solarbio Science \& Technology Co., Ltd., Beijing, China). Protein concentration was analyzed using Pierce Bicinchoninic Acid Protein Assay kit (Pierce; Thermo Fisher Scientific, Inc.). The protein lysate ( $25 \mu \mathrm{g})$ was then separated by $10 \%$ SDS-PAGE and transferred to a polyvinylidene fluoride membrane(EMD Millipore, Billerica, MA,USA). Subsequently, $5 \%$ non-fat milk was applied to block the membrane at $37^{\circ} \mathrm{C}$ for $60 \mathrm{~min}$, and the membrane was incubated with anti-TGM2 (cat. no. ab216018, 1:800; Abcam, Cambridge, MA, USA), anti-tissue inhibitor of metalloproteinases-2 (TIMP-2; cat. no. ab180630, 1:1,000; Abcam), anti-matrix metalloproteinase (MMP)-2 (cat. no. ab37150, 1:1,200; Abcam), anti-MMP-9 (cat. no. ab73734, 1:600; Abcam), anti-E-cadherin (cat. no. ab15148, 1:800; Abcam), anti-phosphorylated (p)-PI3K (cat. no. ab138364, 1:600; Abcam), anti-PI3K (cat. no. MAB2686, 1:600; R\&D Systems, Inc.), anti-p-protein kinase B (Akt; cat. no. MAB887, 1:800; R\&D Systems, Inc.), anti-Akt (cat. no. MAB2055, 1:800; R\&D Systems, Inc.) and anti-GAPDH (cat. no. ab181602, 1:600; Abcam) at $4^{\circ} \mathrm{C}$ overnight. The membrane was then incubated with corresponding secondary antibodies [goat anti-mouse immunoglobulin (Ig) G H\&L, cat. no. ab6708, 1:6,000; goat anti-rabbit IgG $\mathrm{H} \& \mathrm{~L}$ (horseradish peroxidase), cat. no. ab6721, 1:7,000; Abcam) at $37^{\circ} \mathrm{C}$ for $60 \mathrm{~min}$. The proteins were visualized using an enhanced chemiluminescence system (GE Healthcare, Chicago, IL, USA). The protein levels were quantified using Bio-Rad ChemiDoc system with Image Lab software (version 6.0 Bio-Rad Laboratories, Inc., Hercules, CA, USA).

Cell Counting kit-8 (CCK-8) analysis. LoVo cells were inoculated in a 96 -well plate $\left(3 \times 10^{3}\right.$ cell/well) in an incubator at $37^{\circ} \mathrm{C}$ for $24 \mathrm{~h}$. After culturing, cells were treated with PBS (control group), or were transfected with miRNA mimics (mock group) or miR-214 mimics (mimics group) for $48 \mathrm{~h}$. Subsequently, $10 \mu$ l CCK-8 reagent (Beyotime Institute of Biotechnology) 
Table I. Primer sequences for reverse transcription-quantitative polymerase chain reaction.

\begin{tabular}{llc}
\hline Primer name & \multicolumn{1}{c}{ Sequence (5'-3') } & Product size (bp) \\
\hline miR-214-Forward & ATAGAATTCTTTCTCCCTTTCCCCTACTCTCC & 235 \\
miR-214-Reverse & CCAGGATCCTTTCATAGGCACCACTCACTTTAC & 236 \\
TGM2-Forward & CCGAGGAGCTGGTCTTAGAG & 236 \\
TGM2-Reverse & TCTTAGTGGAAAACGGGCCT & 180 \\
E-cadherin-Forward & TTTGAAGATTGCACCGGTCG & 175 \\
E-cadherin- Reverse & CAGCGTGACTTTGGTGGAAA & 184 \\
TIMP-2-Forward & AGCACCACCCAGAAGAAGAG & 238 \\
TIMP-2-Reverse & TGATGCAGGCGAAGAACTTG & 215 \\
MMP-2-Forward & TGGCTACACACCTGATCTGG & 2 \\
MMP-2-Reverse & GAGTCCGTCCTTACCGTCAA & 22 \\
MMP-9-Forward & GAGACTCTACACCCAGGACG & 2 \\
MMP-9-Reverse & GAAAGTGAAGGGGAAGACGC & \\
U6-Forward & CTCGCTTCGGCAGCACA & \\
U6-Reverse & AACGCTTCACGAATTGCGT & \\
GAPDH-Forward & CCATCTTCCAGGAGCGAGAT & \\
GAPDH-Reverse & TGCTGATGATCTTGAGGCTG & \\
\hline
\end{tabular}

miR-214, microRNA-214; MMP, matrix metalloproteinase; TGM2, transglutaminase 2; TIMP-2, tissue inhibitor of metalloproteinases-2.

was added into each well, and cells were incubated with CCK- 8 reagent for $4 \mathrm{~h}$ at $37^{\circ} \mathrm{C}$. Cell viability was determined at $450 \mathrm{~nm}$ using a microplate absorbance spectrophotometer (Bio-Rad Laboratories, Inc.).

Transwell analysis. Migration and invasion of cells were determined using Transwell analysis. Cell invasion was measured using Matrigel-coated Transwell chambers (BD Biosciences, Franklin Lakes, NJ, USA), and cell migration was measured using uncoated Transwell chambers (BD Biosciences). Invasion assay was performed using Transwell inserts pre-coated with Matrigel (BD Biosciences). RPMI-1640 medium supplemented with 12\% FBS was added to the lower chamber. The treated cells were digested with trypsin and a cell $\left(2 \times 10^{5}\right.$ cells $\left./ \mathrm{ml}\right)$ suspension was incubated in the upper chamber at $37^{\circ} \mathrm{C}$ for $24 \mathrm{~h}$. Subsequently, the cells were fixed with $4 \%$ paraformaldehyde at room temperature for $15 \mathrm{~min}$ and stained with $0.1 \%$ crystal violet for $20 \mathrm{~min}$ at room temperature. The stained cells were observed under a light microscope (magnification, x200).

Statistical analysis. SPSS 20.0 software was used to conduct statistical analysis. Data are presented as the means \pm standard deviation. Differences among the groups were analyzed by one-way analysis of variance followed by Tukey test. Differences between two groups were analyzed by Student's t-test. The association between TGM2 expression and the clinicopathological features of patients with CRC was investigated using $\chi^{2}$ test. The correlation between miR-214 and TGM2 expression in CRC was determined using the two-tailed Spearman nonparametric correlation test. $\mathrm{P}<0.05$ was considered to indicate a statistically significant difference. All experiments were repeated independently at least three times.

\section{Results}

TGM2 was the target gene for miR-214 in CRC. The expression levels of miR-214 and TGM2 were detected in CRC and adjacent normal tissues using RT-qPCR and western blotting. Compared with in adjacent normal tissues, the expression levels of miR-214 were decreased in CRC tissues; however, TGM2 expression was increased (Fig. 1A-C). Two-tailed Spearman nonparametric correlation test identified a negative correlation between miR-214 and TGM2 expression in CRC tissues (Fig. 1D). When LoVo cells were transfected with miR-214 mimics, miR-214 expression was enhanced, whereas the mRNA and protein expression levels of TGM2 were suppressed (Fig. 1E-G). According to TargetScan (http://www. targetscan.org/vert_72/), miR-214 possessed TGM2 binding sites (Fig. $1 \mathrm{H}$ ); therefore, the binding abilities of miR-214 and TGM2 were tested using a dual luciferase reporter assay. Although relative luciferase activity was reduced in cells exposed to miR-214 mimics and TGM2-3'UTR, it remained relatively stable in cells co-transfected with miR-214 + TGM2-3'UTR mut (Fig. 1I). Furthermore, TGM2 expression was divided into a low expression group and a high expression group according to the median value of relative expression, and the results of a $\chi^{2}$ test revealed that TGM2 expression was associated with lymph node metastasis; however, it was not associated with age, sex, tumor location or tumor type (Table II).

miR-214 suppresses the viability, migration and invasiveness of LoVo cells. CCK-8 and Transwell assays were performed to explore the effect of miR-214 on the viability, migration and invasion of LoVo cells. CCK-8 results revealed that miR-214 overexpression inhibited cell viability compared with in the 
Table II. Association between TGM2 expression and the clinicopathological features of patients with colorectal cancer.

\begin{tabular}{|c|c|c|c|}
\hline Variables & $\begin{array}{c}\text { Low TGM2 } \\
\text { expression }(n=17)\end{array}$ & $\begin{array}{c}\text { High TGM2 } \\
\text { expression }(n=19)\end{array}$ & P-value \\
\hline Age (years) & & & 0.738 \\
\hline$<60$ & 8 & 10 & \\
\hline$\geq 60$ & 9 & 9 & \\
\hline Sex & & & 0.549 \\
\hline Male & 10 & 13 & \\
\hline Female & 7 & 6 & \\
\hline Tumor location & & & 0.955 \\
\hline Colon & 10 & 11 & \\
\hline Rectum & 7 & 8 & \\
\hline Tumor size & & & 0.271 \\
\hline$<30 \mathrm{~mm}$ & 15 & 14 & \\
\hline$\geq 30 \mathrm{~mm}$ & 2 & 5 & \\
\hline Lymph node metastasis & & & $0.019^{\mathrm{a}}$ \\
\hline No & 12 & 6 & \\
\hline Yes & 5 & 13 & \\
\hline
\end{tabular}

${ }^{\mathrm{a}} \mathrm{P}<0.05, \chi^{2}$ test.

mock group (Fig. 2A). Transwell results demonstrated that when cells were exposed to miR-214 mimics, the relative rates of migration (Fig. 2B) and invasion (Fig. 2C) were markedly reduced compared with in the mock group.

miR-214 regulates EMT-associated factors in LoVo cells. To examine the molecular mechanism underlying the effects of miR-214 on cell migration and invasion, the expression levels of EMT-associated factors (TIMP-2, MMP-2, MMP-9 and E-cadherin) were detected by RT-qPCR and western blotting. As determined by RT-qPCR, the expression levels of TIMP-2 and E-cadherin were enhanced in the mimics group; however, MMP-2 and MMP-9 expression was inhibited compared with in the mock group (Fig. 3A-D). In addition, as determined by western blotting, miR-214 overexpression significantly suppressed the protein expression levels of MMP-2 and MMP-9, but promoted TIMP-2 and E-cadherin expression (Fig. 3E).

miR-214 blocks the PI3K/Akt signaling pathway in LoVo cells. In order to assess the effects of miR-214 on signaling in LoVo cells, the PI3K/Akt signaling pathway was analyzed by western blotting. The results revealed that phosphorylation of PI3K and Akt were significantly reduced when cells were exposed to miR-214 mimics, compared with in the control and mock groups $(\mathrm{P}<0.01)$. Nevertheless, the protein expression levels of total $\mathrm{PI} 3 \mathrm{~K}$ and Akt remained stable in all groups (Fig. 4A and B). In addition, the PI3K activator IGF-1 was used to further detect the role of PI3K/Akt signaling; the results revealed that MMP-9 expression was upregulated, whereas TIMP-2 expression was decreased in the IGF-1 + mimic group compared with in the mimic group. These findings indicated that the effects of miR-214 on cell invasion and migration may be partly associated with inhibition of PI3K/Akt signaling (Fig. 5).

\section{Discussion}

miR-214 has been reported to be particularly active in cancer, being abnormally expressed in several types of malignant tumors (27-29). However, the expression of miR-214 varies in different tumors, and has certain tumor specificity. Specifically, miR-214 has been demonstrated to have a high expression in pancreatic cancer, oophoroma and melanoma (30-32), and a low expression in esophageal squamous cell carcinoma, liver cancer, breast cancer, cervical carcinoma and CRC (33-37). In the present study, low miR-214 expression was detected in CRC tissues, which was in accordance with the results of previous studies $(33,38)$.

As a member of the transglutaminase family, TGM2 is composed of 687 amino acid residues, and is a calcium-dependent multifunctional protein with a molecular weight of $78 \mathrm{kD}$ (39). Numerous studies have demonstrated that TGM2 expression is closely associated with the proliferation and metastasis of various malignant tumor cells (40-43). TGM2 expression is increased in breast cancer, ovarian cancer, lung cancer and CRC (44-47). Similar to previous findings (45), the present data also demonstrated that TGM2 expression was increased in CRC tissues. It is well known that different miRNAs can regulate the same mRNA molecule, and that the same miRNA can regulate numerous mRNA molecules. In this study, the results of a two-tailed Spearman nonparametric correlation test identified a negative correlation between miR-214 and TGM2 expression in CRC. Furthermore, overexpression of miR-214 significantly inhibited the expression levels of TGM2. Therefore, it may be speculated that TGM2 acts as 
A
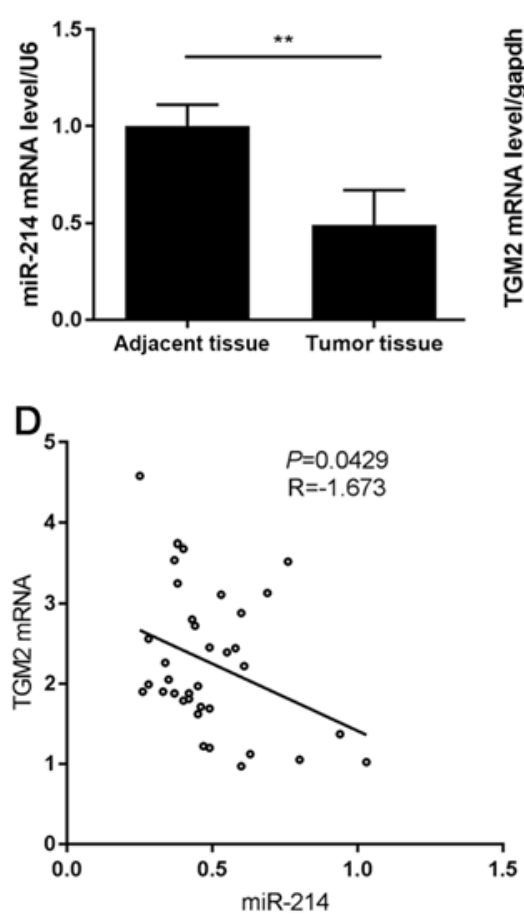

G

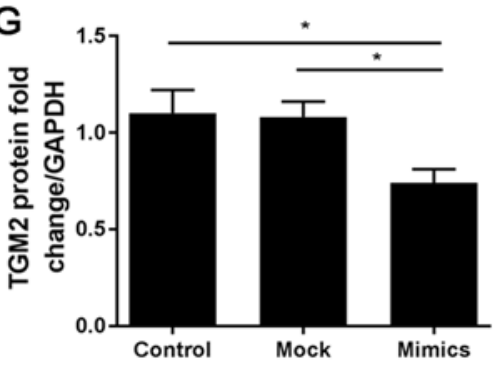

TGM2

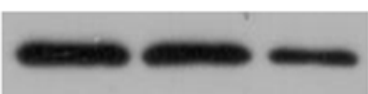

GAPDH
B

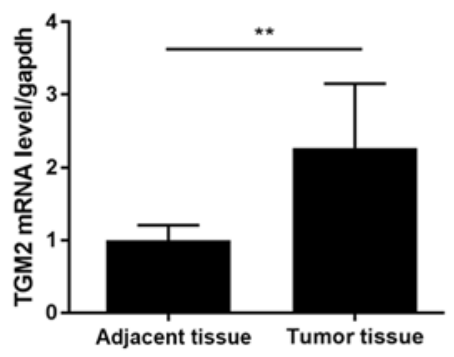

E

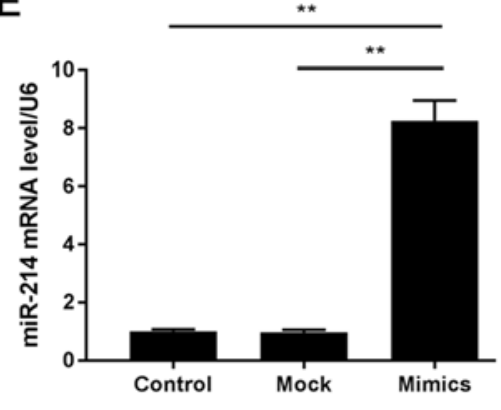

C

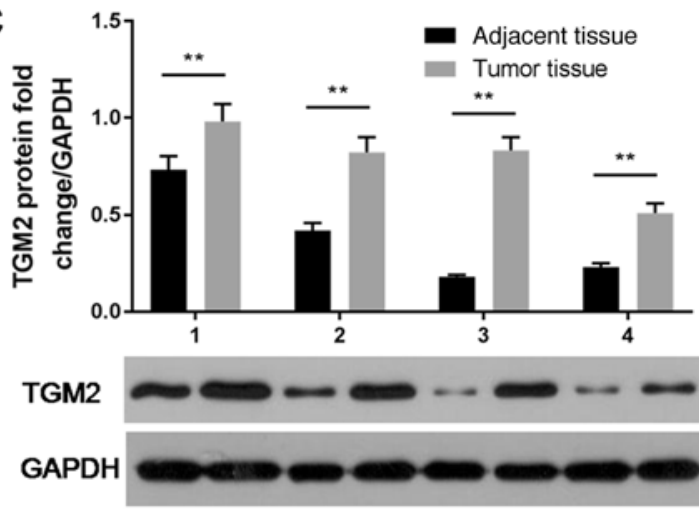

F

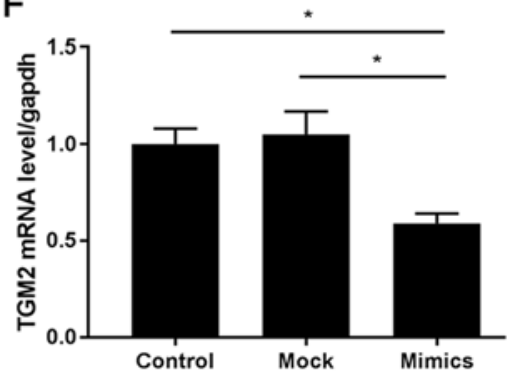

$\mathrm{H}$

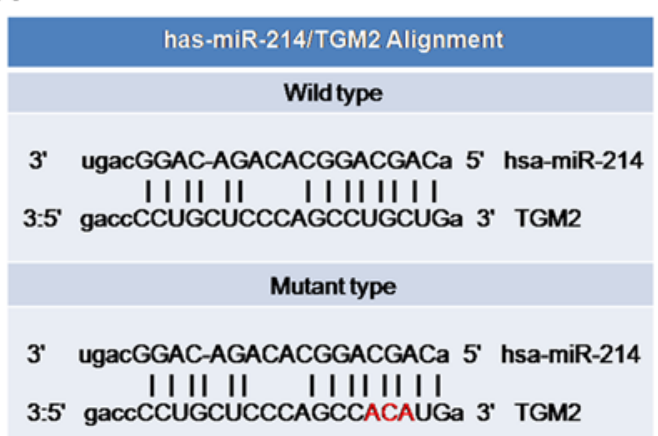

I

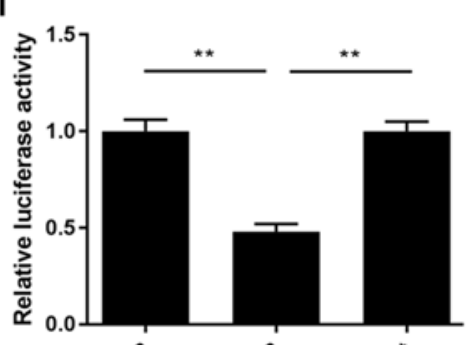

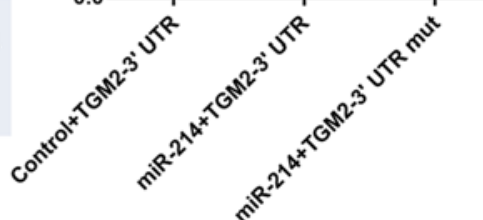

Figure 1. TGM2 is a target gene of miR-214 in CRC. (A-C) mRNA and protein expression levels of miR-214 and TGM2 in CRC and adjacent normal tissues, as determined by (A and B) RT-qPCR and (C) western blotting. (D) Correlation between miR-214 and TGM2 expression in CRC, as determined by two-tailed Spearman nonparametric correlation test. (E-G) LoVo cells were treated with PBS (control group), or were transfected with miRNA mimics (mock group) or miR-214 mimics (mimics group). Expression levels of miR-214 and TGM2 were examined by (E and F) RT-qPCR and (G) western blotting. (H) TGM2 binding site in miR-214 was predicted by TargetScan. (I) Luciferase activity was measured by dual luciferase reporter assay. ${ }^{*} \mathrm{P}<0.05{ }^{* * *} \mathrm{P}<0.01 .3^{\prime} \mathrm{UTR}, 3^{\prime}-\mathrm{untranslated}^{\prime}$ region; CRC, colorectal carcinoma; miR-214, microRNA-214; mut, mutant; RT-qPCR, reverse transcription-quantitative polymerase chain reaction; TGM2, transglutaminase 2 .

a target gene for miR-214 in CRC. According to TargetScan, miR-214 possesses a binding site to TGM2. Additionally, luciferase activity was reduced in cells co-transfected with miR-214 + TGM2-3'UTR; however, it remained stable in cells co-transfected with miR-214 + TGM2-3'UTR mut compared with in the control + TGM2-3'UTR group. These results confirmed that TGM2 was a target of miR-214.

Previous studies have reported that abnormal miRNA expression exists in several human diseases, and that it serves a pivotal role in the occurrence, development, invasion, metastasis and angiogenesis of cancer (15,18-20). Furthermore, miR-214 participates in the growth, invasion and metastasis of cancer. Lu et al (48) demonstrated that miR-214 suppresses cell invasion and migration in esophageal squamous cell cancer. Zhao et al (49) also revealed that miR-214 inhibits the growth and metastasis of lung cancer cells, and Schwarzenbach et al (35) demonstrated that miR-214 inhibits the proliferation and metastasis of cervical cancer and CRC cells. Similarly, the present data demonstrated that miR-214 markedly suppressed the viability, invasiveness and migration of LoVo cells. Notably, decreased cell invasion and migration may be partially caused by inhibited cell viability.

Li et al (50) reported that decreased expression of miR-214 promotes intrahepatic cholangiocarcinoma metastasis via regulating EMT-related factors (Twist and E-cadherin). Cai et al (51) also demonstrated that miR-194 increases cell metastasis and modulates the EMT process by reducing E-cadherin levels and increasing MMP-2 levels in 

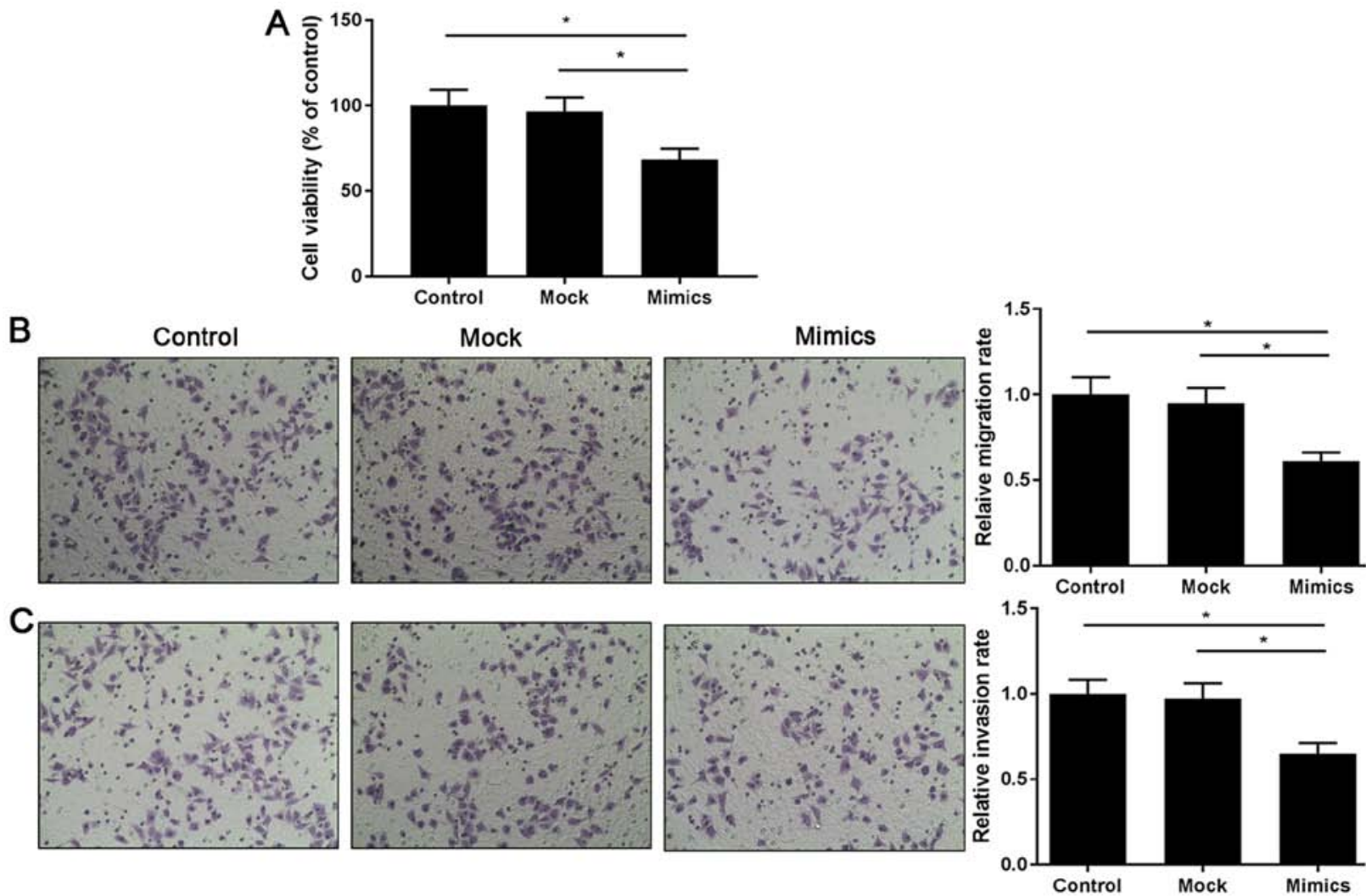

Figure 2. MicroRNA-214 suppresses the viability, migration and invasiveness of LoVo cells. (A) Cell viability was analyzed by Cell Counting kit-8 assay. Cell (B) migration and (C) invasion were determined by Transwell assay (magnification, $\mathrm{x} 200$ ). ${ }^{*} \mathrm{P}<0.05$.
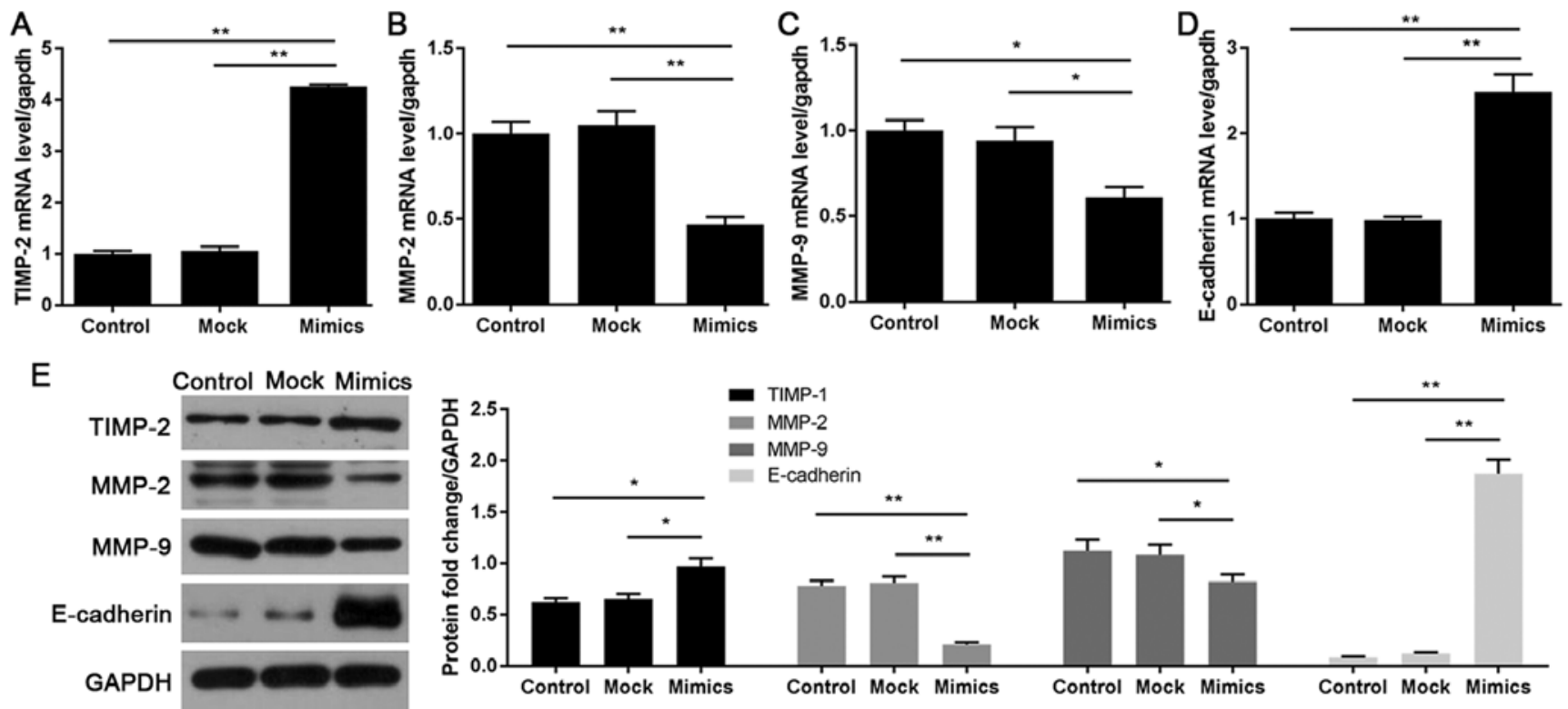

Figure 3. MicroRNA-214 regulates epithelial-mesenchymal transition-associated factors in LoVo cells. (A-D) Reverse transcription-quantitative polymerase chain reaction was used to determine the mRNA expression levels of (A) TIMP-2, (B) MMP-2, (C) MMP-9 and (D) E-cadherin. (E) Western blotting was used to examine the protein expression levels of TIMP-2, MMP-2, MMP-9 and E-cadherin. ${ }^{*} \mathrm{P}<0.05,{ }^{* *} \mathrm{P}<0.01$. MMP, matrix metalloproteinase; TIMP-2, tissue inhibitor of metalloproteinases-2.

CRC. Another study observed that miR-29b inhibits EMT via affecting the expression of E-cadherin, MMPs and TIMPs (52). Therefore, it was hypothesized that miR-214 may suppress the invasion and migration of LoVo cells via regulating EMT-associated factors (E-cadherin, MMPs and TIMPs). As expected, this study revealed that elevated expression of miR-214 markedly increased the expression levels of TIMP-2 and E-cadherin, and reduced MMP-2 and MMP-9 expression. The results suggested that miR-214 inhibited cell invasion and migration through downregulating 

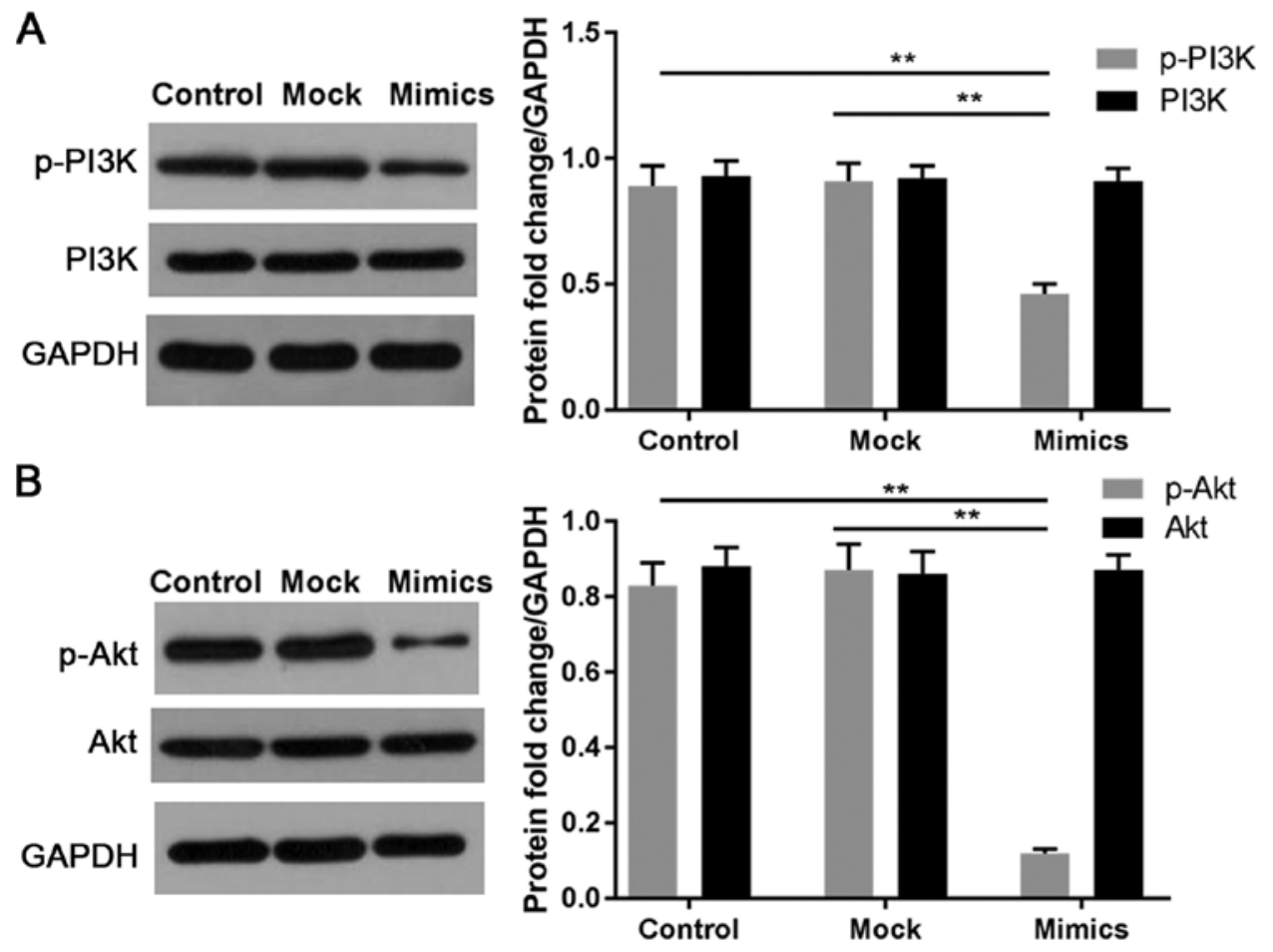

Figure 4. MicroRNA-214 suppresses PI3K/Akt signaling in LoVo cells. Protein expression levels of (A) p-PI3K and PI3K, and (B) p-Akt and Akt, as determined by western blotting. ${ }^{* *} \mathrm{P}<0.01$. Akt, protein kinase B; $\mathrm{p}$-, phosphorylated; PI3K, phosphoinositide 3-kinase.

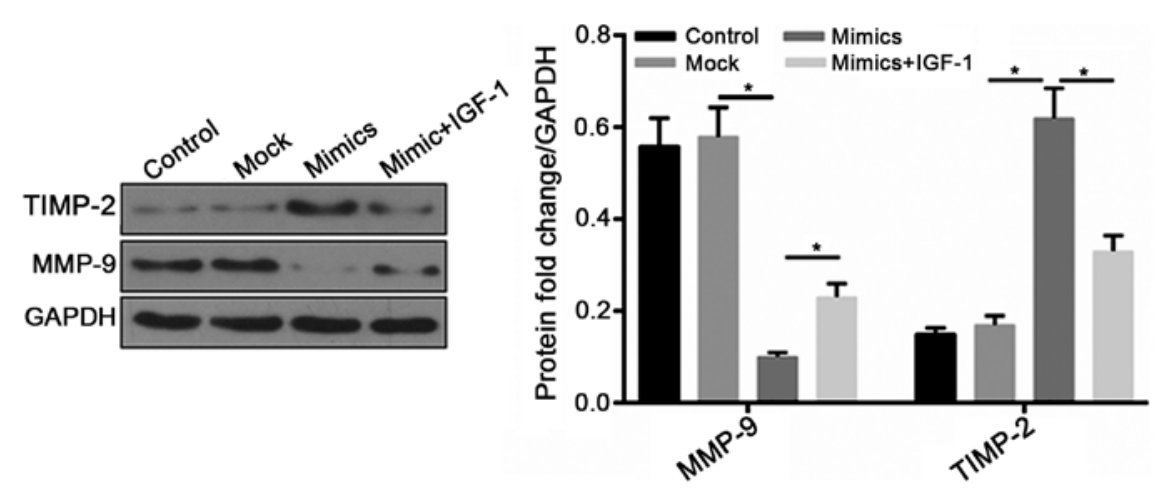

Figure 5. Activation of PI3K reverses the effects of microRNA-214 on LoVo cells. The protein expression levels of MMP-9 and TIMP-2 were assessed by western blotting. "P<0.05. IGF-1, insulin-like growth factor 1; MMP-9, matrix metalloproteinase-9; TIMP-2, tissue inhibitor of metalloproteinases-2.

MMP-2 and MMP-9 expression and by upregulating TIMP-2 and E-cadherin expression.

The PI3K/Akt signaling pathway has been increasingly studied in CRC. The pathway serves a critical role in the development of CRC and may be used for the development of novel drugs: PI3K/Akt pathway may potentially be used as a drug target for CRC, as pathway inhibitors may promote apoptosis and inhibit proliferation of CRC cells. Activation of this pathway can inhibit the apoptosis of CRC cells, and promote cell proliferation, invasion and metastasis (53-55). A previous have reported that GDC-0941, a novel class I PI3K inhibitor, can enhance the efficacy of docetaxel by increasing drug-induced apoptosis in breast cancer models (56). Abubaker et al (53) reported that activation of the PI3K/Akt pathway stimulates cell growth in CRC. Song et al (55) demonstrated that miR-532 attenuates PI3K/Akt signaling to suppress the progression of CRC (55). Jia et al (57) confirmed that miR-182 and miR-135b suppress cell proliferation and motility through inhibiting the PI3K/Akt pathway in CRC. Therefore, in this study, the effects of miR-214 on the PI3K/Akt pathway were examined in LoVo cells via western blotting. The results confirmed that miR-214 suppressed activation of PI3K/Akt signaling. Furthermore, activation of PI3K/Akt reversed the effects of miR-214 on the expression levels of MMP-9 and TIMP-2. Therefore, these findings suggested that inhibition of the PI3K/Akt pathway may be associated with the antitumor effect of miR-214.

In conclusion, the present results demonstrated that TGM2 was a target gene for mi-214, and that a negative correlation existed between miR-214 and TGM2 expression in CRC. miR-214 markedly suppressed the viability, migration and invasion of CRC cells, which was associated with downregulation of the PI3K/Akt signaling pathway. These findings indicated that miR-214 may be considered a novel target for CRC therapy. 


\section{Acknowledgements}

Not applicable.

\section{Funding}

No funding was received.

\section{Availability of data and materials}

The datasets used and/or analyzed during the present study are available from the corresponding author on reasonable request.

\section{Authors' contributions}

HS wrote the manuscript. HS, XFZ and CJC performed the experiments and data analysis. HS and CJC designed the study and revised the manuscript. All authors reviewed the manuscript.

\section{Ethics approval and consent to participate}

The present study was approved by the Ethics Committee of The Affiliated Dongtai Hospital of Nantong University. Patients provided written informed consent permitting their tissues to be used.

\section{Patient consent for publication}

Informed consent was obtained from all participants for the publication of their data.

\section{Competing interests}

The authors declare that they have no competing interests.

\section{References}

1. Peng BJ, Cao CY, Li W, Zhou YJ, Zhang Y, Nie YQ, Cao YW and Li YY: Diagnostic performance of intestinal fusobacterium nucleatum in colorectal cancer: A meta-analysis. Chin Med J (Engl) 131: 1349-1356, 2018.

2. Parkin DM, Bray F, Ferlay J and Pisani P: Global cancer statistics, 2002. CA Cancer J Clini 55: 74-108, 2005.

3. Liao Y, Li S, Chen C, He X, Lin F, Wang J, Yang Z and Lan P: Screening for colorectal cancer in Tianhe, Guangzhou: Results of combining fecal immunochemical tests and risk factors for selecting patients requiring colonoscopy. Gastroenterol Rep (Oxf) 6: 132-136, 2018

4. Sun J, Hu J, Wang G, Yang Z, Zhao C, Zhang X and Wang J: LncRNA TUG1 promoted KIAA1199 expression via miR-600 to accelerate cell metastasis and epithelial-mesenchymal transition in colorectal cancer. J Exp Clini Cancer Res 37: 106, 2018.

5. Wang H, Yao L, Gong Y and Zhang B: TRIM31 regulates chronic inflammation via NF- $\mathrm{BB}$ signal pathway to promote invasion and metastasis in colorectal cancer. Am J Transl Res 10: 1247-1259, 2018.

6. Wang JL, Guo CR, Su WY, Chen YX, Xu J and Fang JY: CD24 overexpression related to lymph node invasion and poor prognosis of colorectal cancer. Clin Lab 64: 497-505, 2018.

7. Hua Q, Mi B and Huang G: The emerging co-regulatory role of long noncoding RNAs in epithelial-mesenchymal transition and the Warburg effect in aggressive tumors. Crit Rev Oncol Hematol 126: 112-120, 2018.

8. Lamouille S, Xu J and Derynck R: Molecular mechanisms of epithelial-mesenchymal transition. Nat Rev Mol Cell Biol 15: 178-196, 2014.
9. Cai Z, Cao Y, Luo Y, Hu H and Ling H: Signalling mechanism(s) of epithelial-mesenchymal transition and cancer stem cells in tumour therapeutic resistance. Clin Chim Acta 483: 156-163, 2018.

10. Maeda $\mathrm{S}$ and Nakagawa $\mathrm{H}$ : Roles of E-cadherin in Hepatocarcinogenesis. In: Innovative Medicine: Basic research and development. Nakao K, Minato $\mathrm{N}$ and Uemoto S (eds). Springer, Tokyo, pp71-77, 2015

11. Chi Y, Huang Q, Lin Y, Ye G, Zhu H and Dong S: Epithelial-mesenchymal transition effect of fine particulate matter from the Yangtze River Delta region in China on human bronchial epithelial cells. J Environ Sci (China) 66: 155-164, 2018.

12. He J, Tang F, Liu L, Chen L, Li J, Ou D, Zhang L, Li Z, Feng D, $\mathrm{Li} \mathrm{W}$ and Sun LQ: Positive regulation of TAZ expression by EBV-LMP1 contributes to cell proliferation and epithelial-mesenchymal transition in nasopharyngeal carcinoma. Oncotarget 8: 52333-52344, 2016.

13. Zhou WJ, Chen J, Feng Y, Fan YP, Li Q, Fu J and Zhang P: Inhibition of cigarettes smoke-induced epithelial to mesenchymal transition by the SMO inhibitor PF-5274857 in Beas-2b epithelial cells. Sichuan Da Xue Xue Bao Yi Xue Ban 47: 485-490, 2016 (In Chinese).

14. Haider MT and Taipaleenmäki H: Targeting the metastatic bone microenvironment by MicroRNAs. Front Endocrinol (Lausanne) 9: 202, 2018.

15. Amarilyo G, Pillar N, Ben-Zvi I, Weissglas-Volkov D, Zalcman J, Harel L, Livneh A and Shomron N: Analysis of microRNAs in familial mediterranean fever. PLoS One 13: e0197829, 2018.

16. De Los Reyes-Garcia AM, Arroyo AB, Teruel-Montoya R, Vicente V, Lozano ML, González-Conejero R and Martinez C: MicroRNAs as potential regulators of platelet function and bleeding diatheses. Platelets: 1-6, 2018 (Epub ahead of print).

17. Li Y, Duo Y, Bi J, Zeng X, Mei L, Bao S, He L, Shan A, Zhang Y and $\mathrm{Yu} \mathrm{X}$ : Targeted delivery of anti-miR-155 by functionalized mesoporous silica nanoparticles for colorectal cancer therapy. Int J Nanomedicine 13: 1241-1256, 2018.

18. Lin Y, Chen F, Shen L, Tang X, Du C, Sun Z, Ding H, Chen J and Shen B: Biomarker microRNAs for prostate cancer metastasis: Screened with a network vulnerability analysis model. J Transl Med 16: 134, 2018.

19. Tu J and Zhang YS: Advance on microRNA and prostate cancer. Zhonghua Bing Li Xue Za Zhi 47: 388-390, 2018 (In Chinese).

20. Vera O, Jimenez J, Pernia O, Rodriguez-Antolin C, Rodriguez C, Sanchez Cabo F, Soto J, Rosas R, Lopez-Magallon S, Esteban Rodriguez I, et al: DNA methylation of miR-7 is a mechanism involved in platinum response through MAFG overexpression in cancer cells. Theranostics 7: 4118-4134, 2017.

21. Hong-Yuan W and Xiao-Ping C: miR-338-3p suppresses epithelial-mesenchymal transition and metastasis in human nonsmall cell lung cancer. Indian J Cancer 52 (Suppl 3): E168-E171, 2015.

22. Li Y, An H, Pang J, Huang L, Li J and Liu L: MicroRNA profiling identifies miR-129-5p as a regulator of EMT in tubular epithelial cells. Int J Clin Exp Med 8: 20610-20616, 2015.

23. Lili LN, Huang AD, Zhang M, Wang L, McDonald LD, Matyunina LV, Satpathy $M$ and McDonald JF: Time-course analysis of microRNA-induced mesenchymal-to-epithelial transition underscores the complexity of the underlying molecular processes. Cancer Lett 428: 184-191, 2018.

24. Penna E, Orso F and Taverna D: miR-214 as a key hub that controls cancer networks: Small player, multiple functions. J Invest Dermatol 135: 960-969, 2015.

25. Alonso L, Okada H, Pasolli HA, Wakeham A, You-Ten AI, Mak TW and Fuchs E: Sgk3 links growth factor signaling to maintenance of progenitor cells in the hair follicle. J Cell Biol 170: 559-570, 2005.

26. Livak KJ and Schmittgen TD: Analysis of relative gene expression data using real-time quantitative PCR and the 2(-Delta Delta C(T)) method. Methods 25: 402-408, 2001.

27. Liu Y, Zhou H, Ma L, Hou Y, Pan J, Sun C, Yang Y and Zhang J: MiR-214 suppressed ovarian cancer and negatively regulated semaphorin 4D. Tumour Biol 37: 8239-8248, 2016.

28. Yang TS, Yang XH, Wang XD, Wang YL, Zhou B and Song ZS: MiR-214 regulate gastric cancer cell proliferation, migration and invasion by targeting PTEN. Cancer Cell Int 13: 68, 2013.

29. Wang X, Chen J, Li F, Lin Y, Zhang X, Lv Z and Jiang J: MiR-214 inhibits cell growth in hepatocellular carcinoma through suppression of beta-catenin. Biochem Biophys Res Commun 428: 525-531, 2012. 
30. Penna E, Orso F, Cimino D, Tenaglia E, Lembo A, Quaglino E, Poliseno L, Haimovic A, Osella-Abate S, De Pitta C, et al: microRNA-214 contributes to melanoma tumour progression through suppression of TFAP2C. EMBO J 30: 1990-2007, 2011.

31. Yang H, Kong W, He L, Zhao JJ, O'Donnell JD, Wang J, Wenham RM, Coppola D, Kruk PA, Nicosia SV, et al: MicroRNA expression profiling in human ovarian cancer: miR-214 induces cell survival and cisplatin resistance by targeting PTEN. Cancer Res 68: 425-433, 2008.

32. Zhang XJ, Ye H, Zeng CW, He B, Zhang $\mathrm{H}$ and Chen YQ Dysregulation of miR-15a and miR-214 in human pancreatic cancer. J Hematol Oncol 3: 46, 2010.

33. Chandrasekaran KS, Sathyanarayanan A and Karunagaran D: miR-214 activates TP53 but suppresses the expression of RELA, CTNNB1, and STAT3 in human cervical and colorectal cancer cells. Cell Biochem Funct 35: 464-471, 2017.

34. Huang SD, Yuan Y, Zhuang CW, Li BL, Gong DJ, Wang SG, Zeng ZY and Cheng HZ: MicroRNA-98 and microRNA-214 post-transcriptionally regulate enhancer of zeste homolog 2 and inhibit migration and invasion in human esophageal squamous cell carcinoma. Mol Cancer 11: 51, 2012.

35. Schwarzenbach H, Milde-Langosch K, Steinbach B, Müller V and Pantel K: Diagnostic potential of PTEN-targeting miR-214 in the blood of breast cancer patients. Breast Cancer Res Treat 134 933-941, 2012.

36. Shih TC, Tien YJ, Wen CJ, Yeh TS, Yu MC, Huang $\mathrm{CH}$, Lee YS, Yen TC and Hsieh SY: MicroRNA-214 downregulation contributes to tumor angiogenesis by inducing secretion of the hepatoma-derived growth factor in human hepatoma. J Hepatol 57: 584-591, 2012.

37. Yang Z, Chen S, Luan X, Li Y, Liu M, Li X, Liu T and Tang H: MicroRNA-214 is aberrantly expressed in cervical cancers and inhibits the growth of HeLa cells. IUBMB Life 61: 1075-1082, 2009.

38. Chandrasekaran KS, Sathyanarayanan A and Karunagaran D: MicroRNA-214 suppresses growth, migration and invasion through a novel target, high mobility group AT-hook 1, in human cervical and colorectal cancer cells. Br J Cancer 115: 741-751, 2016.

39. Lorand L and Graham RM: Transglutaminases: Crosslinking enzymes with pleiotropic functions. Nat Rev Mol Cell Biol 4: 140-156, 2003

40. Kang S, Oh SC, Min BW and Lee DH: Transglutaminase 2 regulates self-renewal and stem cell marker of human colorectal cancer stem cells. Anticancer Res 38: 787-794, 2018.

41. Yamaguchi H, Kuroda K, Sugitani M, Takayama T, Hasegawa K and Esumi M: Transglutaminase 2 is upregulated in primary hepatocellular carcinoma with early recurrence as determined by proteomic profiles. Int J Oncol 50: 1749-1759, 2017.

42. Yin J, Oh YT, Kim JY, Kim SS, Choi E, Kim TH, Hong JH, Chang N, Cho HJ, Sa JK, et al: Transglutaminase 2 Inhibition reverses mesenchymal transdifferentiation of glioma stem cells by regulating C/EBPbeta signaling. Cancer Res 77: 4973-4984, 2017.

43. Zonca S, Pinton G, Wang Z, Soluri MF, Tavian D, Griffin M, Sblattero D and Moro L: Tissue transglutaminase (TG2) enables survival of human malignant pleural mesothelioma cells in hypoxia. Cell Death Dis 8: e2592, 2017.

44. Fang Q, Yao S, Luo G and Zhang X: Identification of differentially expressed genes in human breast cancer cells induced by 4-hydroxyltamoxifen and elucidation of their pathophysiological relevance and mechanisms. Oncotarget 9: 2475-2501, 2018.
45. Miyoshi N, Ishii H, Mimori K, Tanaka F, Hitora T, Tei M, Sekimoto M, Doki Y and Mori M: TGM2 is a novel marker for prognosis and therapeutic target in colorectal cancer. Ann Surg Oncol 17: 967-972, 2010.

46. Park KS, Kim HK, Lee JH, Choi YB, Park SY, Yang SH, Kim SY and Hong KM: Transglutaminase 2 as a cisplatin resistance marker in non-small cell lung cancer. J Cancer Res Clin Oncol 36: 493-502, 2010.

47. Sodek KL, Ringuette MJ and Brown TJ: Compact spheroid formation by ovarian cancer cells is associated with contractile behavior and an invasive phenotype. Int J Cancer 124: 2060-2070, 2009.

48. Lu Q, Xu L, Li C, Yuan Y, Huang S and Chen H: miR-214 inhibits invasion and migration via downregulating GALNT7 in esophageal squamous cell cancer. Tumour Biol 37: 14605-14614, 2016.

49. Zhao X, Lu C, Chu W, Zhang Y, Zhang B, Zeng Q, Wang R, Li Z Lv B and Liu J: microRNA-214 governs lung cancer growth and metastasis by targeting carboxypeptidase-D. DNA Cell Biol 35: 715-721, 2016.

50. Li B, Han Q, Zhu Y, Yu Y, Wang J and Jiang X: Down-regulation of miR-214 contributes to intrahepatic cholangiocarcinoma metastasis by targeting Twist. FEBS J 279: 2393-2398, 2012.

51. Cai HK, Chen X, Tang YH and Deng YC: MicroRNA-194 modulates epithelial-mesenchymal transition in human colorectal cancer metastasis. OncoTargets Ther 10: 1269-1278, 2017.

52. Yan MD, Yao CJ, Chow JM, Chang CL, Hwang PA, Chuang SE, Whang-Peng J and Lai GM: Fucoidan elevates MicroRNA-29b to regulate DNMT3B-MTSS1 axis and inhibit EMT in human hepatocellular carcinoma cells. Mar Drugs 13: 6099-6116, 2015.

53. Abubaker J, Bavi P, Al-Harbi S, Ibrahim M, Siraj AK, Al-Sanea N, Abduljabbar A, Ashari LH, Alhomoud S, Al-Dayel F, et al: Clinicopathological analysis of colorectal cancers with PIK3CA mutations in Middle Eastern population. Oncogene 27: 3539-3545, 2008.

54. Qin Y, Huo Z, Song X, Chen X, Tian X and Wang X: mir-106a regulates cell proliferation and apoptosis of colon cancer cells through targeting the PTEN/PI3K/AKT signaling pathway. Oncol Lett 15: 3197-3201, 2018.

55. Song Y,Zhao Y, Ding X and Wang X: microRNA-532 suppresses the PI3K/Akt signaling pathway to inhibit colorectal cancer progression by directly targeting IGF-1R. Am J Cancer Res 8: 435-449, 2018.

56. Wallin JJ, Guan J, Prior WW, Lee LB, Berry L, Belmont LD, Koeppen H, Belvin M, Friedman LS and Sampath D: GDC-0941, a novel class I selective PI3K inhibitor, enhances the efficacy of docetaxel in human breast cancer models by increasing cell death in vitro and in vivo. Clin Cancer Res 18: 3901-3911, 2012.

57. Jia L, Luo S, Ren X, Li Y, Hu J, Liu B, Zhao L, Shan Y and Zhou H: miR-182 and miR-135b mediate the tumorigenesis and invasiveness of colorectal cancer cells via targeting ST6GALNAC2 and PI3K/AKT pathway. Dig Dis Sc 62: 3447-3459, 2017.

This work is licensed under a Creative Commons Attribution-NonCommercial-NoDerivatives 4.0 International (CC BY-NC-ND 4.0) License. 